\title{
Induction of Systemic Resistance to Botrytis cinerea in Tomato by Pseudomonas aeruginosa 7NSK2: Role of Salicylic Acid, Pyochelin, and Pyocyanin
}

\author{
Kris Audenaert, ${ }^{1}$ Theresa Pattery, ${ }^{2}$ Pierre Cornelis, ${ }^{2}$ and Monica Höfte ${ }^{1}$ \\ ${ }^{1}$ Laboratory of Phytopathology, Faculty of Agricultural and Applied Biological Sciences, Ghent University, Coupure links, \\ 653, B-9000 Gent, Belgium; ${ }^{2}$ Department of Immunology, Parasitology, and Ultrastructure, Flanders Interuniversity Institute \\ of Biotechnology, Laboratory of Microbial Interactions, Paardenstraat 65 B-1640 Sint Genesius Rode, Vrije Universiteit \\ Brussel, Belgium
}

Submitted 4 February 2002. Accepted 11 July 2002.

\begin{abstract}
The rhizobacterium Pseudomonas aeruginosa 7NSK2 produces secondary metabolites such as pyochelin (Pch), its precursor salicylic acid (SA), and the phenazine compound pyocyanin. Both 7NSK2 and mutant KMPCH (Pch-negative, SA-positive) induced resistance to Botrytis cinerea in wild-type but not in transgenic $N a h G$ tomato. SA-negative mutants of both strains lost the capacity to induce resistance. On tomato roots, KMPCH produced SA and induced phenylalanine ammonia lyase activity, while this was not the case for 7NSK2. In 7NSK2, SA is probably very efficiently converted to Pch. However, Pch alone appeared not to be sufficient to induce resistance. In mammalian cells, Fe-Pch and pyocyanin can act synergistically to generate highly reactive hydroxyl radicals that cause cell damage. Reactive oxygen species are known to play an important role in plant defense. To study the role of pyocyanin in induced resistance, a pyocyanin-negative mutant of 7NSK2, PHZ1, was generated. PHZ1 is mutated in the phzM gene encoding an $O$-methyltransferase. PHZ1 was unable to induce resistance to $B$. cinerea, whereas complementation for pyocyanin production or co-inoculation with mutant 7NSK2-562 (Pch-negative, SA-negative, pyocyaninpositive) restored induced resistance. These results suggest that pyocyanin and Pch, rather than SA, are the determinants for induced resistance in wild-type $P$. aeruginosa 7NSK2.
\end{abstract}

Additional keywords: phenazine-1-carboxylate, siderophores.

Induced resistance is a state of enhanced defensive capacity developed by a plant when appropriately stimulated (van Loon et al. 1998). Induced resistance is generally systemic and can be triggered by pathogens, certain chemicals, and nonpathogenic rhizosphere bacteria. The mechanisms involved in rhizobacteria-mediated induced systemic resistance (ISR) appear to vary among bacterial strains and pathosystems. Bacterial determinants of ISR which have been identified are lipopolysaccharides and siderophores (van Loon et al. 1998). Siderophores are high-affinity iron(III)-chelating compounds that are produced by most microorganisms under iron-limiting conditions. The catechol siderophore biosynthesis genes of Serratia marcescens are involved in ISR to Colletotrichum

Corresponding author: M. Höfte; Telephone: 32-9-2646017; Fax: 32-92646238; E-mail: monica.hofte@ rug.ac.be. orbiculare on cucumber (Press et al. 2001). The purified pyoverdine-type siderophore of Pseudomonas putida WCS374 induced resistance to Fusarium wilt in radish (Leeman et al. 1996), while a pyoverdine-negative mutant of $P$. fluorescens $\mathrm{CHA} 0$ was less effective in inducing resistance to Tobacco necrosis virus on tobacco than the wild-type strain (Maurhofer et al. 1994). Another iron-chelating molecule that is well-studied with respect to induced plant defense is salicylic acid (SA). Although the siderophore capacity of SA is rather poor (Chipperfield and Ratledge 2000), it appears to be an important molecule in induced resistance by the rhizobacterium $P$. aeruginosa 7 NSK2. This bacterium produces three siderophores under iron-limiting conditions (pyoverdine, pyochelin (Pch), and SA) and can induce resistance to plant diseases caused by Botrytis cinerea on bean and tomato (Audenaert et al. 2002; De Meyer et al. 1999b; De Meyer and Höfte 1997), C. lindemuthianum on bean (Bigirimana and Höfte 2002), and Tobacco mosaic virus (TMV) on tobacco (De Meyer et al. 1999a). In all these systems, the involvement of bacterial SA in induced resistance was shown using siderophore mutants. Under iron limitation, SA-deficient mutants were not able to induce resistance in a pyoverdine-negative or -positive background. For $P$. aeruginosa $\mathrm{KMPCH}$, a $\mathrm{Pch}^{-}$and $\mathrm{SA}^{+}$mutant of $P$. aeruginosa $7 \mathrm{NSK} 2$, it was illustrated that bacterial SA induced phenylalanine ammonia lyase (PAL) activity in bean roots (De Meyer et al. 1999b). PAL is a key enzyme in SA biosynthesis and plant defense (Pallas et al. 1996; Smith-Becker et al. 1998). Moreover, SA levels increased in bean leaves upon root colonization with KMPCH. Furthermore, the activation of plant defense by bacterial SA production was mimicked by applying nanogram amounts of exogenous SA to bean roots (De Meyer et al. 1999b). These results clearly demonstrate that the bacterial production of SA by $P$. aeruginosa KMPCH leads to activation of a SA-dependent defense response in plants. In $P$. aeruginosa, SA is produced from chorismate via the shikimate biosynthesis pathway (Serino et al. 1995) and is a direct precursor of Pch. Mutants in SA production also are Pch-negative (Serino et al. 1997); therefore, a role for Pch in induced resistance by the wild-type strain $P$. aeruginosa 7NSK2 cannot be excluded. The resistance-inducing potential of SA was illustrated for other Pseudomonas strains in other plant pathosystems as well. When the SA biosynthetic gene cluster pchDCBA from $P$. aeruginosa PAO1 was introduced into the non-SAproducing strain $P$. fluorescens $\mathrm{P} 3$, the strain was converted into a resistance-inducing strain (Maurhofer et al. 1998). Bac- 
terial SA production, however, does not appear to be involved in disease resistance induced by the rhizobacterium Serratia marcescens 90-166 because an SA-negative mutant of this strain induced resistance to the same level as the wild-type strain (Press et al. 1997).

Most likely, rhizobacteria can induce systemic resistance in plants through different, complementary, and additive mechanisms, of which production of SA represents only one (van Loon et al. 1998).

In the present work, we demonstrate that $P$. aeruginosa $\mathrm{KMPCH}$ induces resistance in tomato to $B$. cinerea through production of SA and through activation of SA-dependent defense mechanisms in the plant as demonstrated earlier in bean by De Meyer and associates (1999b). However, we provide evidence that for the wild-type (WT) strain $P$. aeruginosa 7NSK2 a combined action of Pch and pyocyanin is more likely to be involved in induced resistance to $B$. cinerea in tomato than is SA production. Pyocyanin (5-methyl-1hydroxyphenazinium betaine) is a blue phenazine compound that is only produced by $P$. aeruginosa strains (Turner and Messenger 1986) and is considered to be a virulence factor in clinical isolates of $P$. aeruginosa (Britigan et al. 1992, 1997).

\section{RESULTS}

Involvement of siderophores in induced resistance to $B$. cinerea in tomato plants by $P$. aeruginosa.

Detached tomato leaves were infected with $B$. cinerea using the droplet inoculation method described by Audenaert and associates (2002). The inoculation solution that was used

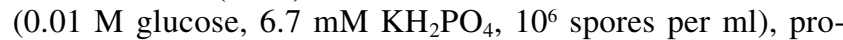
duced a moderate number of spreading lesions in detached leaves from control plants $( \pm 60 \%)$. This infection allowed us to detect decreased disease severity upon root inoculation with resistance-inducing bacterial strains. Root colonization by bacterial strains was determined and was approximately
$10^{5} \mathrm{CFU}$ per $\mathrm{g}$ of fresh root for all bacterial strains at the time of leaf inoculation (data not shown).

In tomato leaves originating from plants colonized by WT $P$. aeruginosa $7 \mathrm{NSK} 2, \mathrm{KMPCH}\left(\mathrm{SA}^{+}, \mathrm{Pch}^{-}\right.$, and pyoverdine ${ }^{-}$ mutant), and MPFM1 ( $\mathrm{SA}^{+}, \mathrm{Pch}^{+}$, but pyoverdine ${ }^{-}$mutant), the number of spreading $B$. cinerea lesions decreased significantly (Fig. 1). Root colonization with the corresponding SA-negative mutants obtained by pchA (encodes one of the enzymes catalyzing the formation of SA from chorismate [Serino et al. 1995]) replacement (7NSK2-562, KMPCH-567 and MPFM1-569) no longer induced resistance (Fig. 1), indicating the involvement of bacterial SA in induced resistance. However, 7NSK2 and MPFM1 both produce Pch from SA; therefore, a role for this siderophore could not be excluded.

\section{KMPCH but not 7NSK2 produces SA on tomato roots.}

To verify in vivo SA-production by KMPCH and 7NSK2, SA levels on tomato roots were determined. KMPCH root colonization resulted in an increased level of free SA $(79.3 \pm 24.7 \mathrm{ng}$ of SA per $\mathrm{g}$ of fresh weight $[\mathrm{FW}])$ compared to control roots (43.1 $\pm 8.9 \mathrm{ng}$ of SA per $\mathrm{g}$ of $\mathrm{FW})$. The SA-negative mutant of $\mathrm{KMPCH}$ (i.e., KMPCH-567) did not result in an increased level of free SA $(37.6 \pm 13.8 \mathrm{ng}$ of SA per $\mathrm{g}$ of $\mathrm{FW})$, indicating that $\mathrm{KMPCH}$ produces SA on tomato roots. Surprisingly, root colonization with 7NSK2 did not result in increased free SA levels $(45.6 \pm 13.6 \mathrm{ng}$ of SA per $\mathrm{g}$ of $\mathrm{FW})$, although this strain produces approximately $6 \mu \mathrm{g}$ of SA per ml when grown on Casamino Acids (CAA) medium (De Meyer and Höfte 1997). No significant differences in bound SA could be observed upon root colonization with the bacterial strains (data not shown).

\section{P. aeruginosa 7NSK2 efficiently converts SA to Pch} in the presence of $L$-cysteine.

We wanted to clarify why SA is produced by 7 NSK 2 in vitro and not on plant roots. One possibility is that SA is efficiently converted to Pch on plant roots. It was shown by Ankenbauer

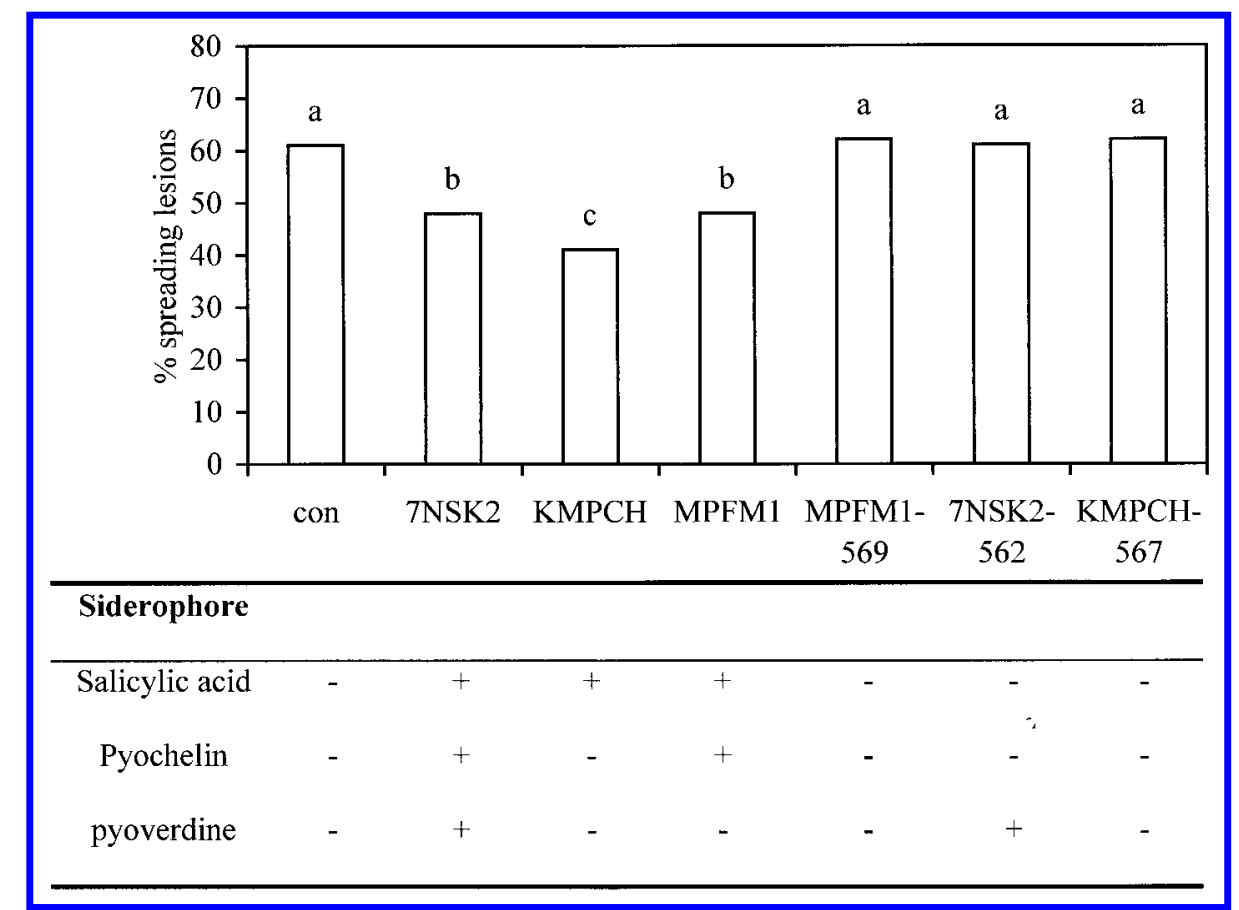

Fig. 1. Influence of tomato root treatment with Pseudomonas aeruginosa 7NSK2 and siderophore mutants on the percentage of spreading Botrytis cinerea lesions on tomato leaves. All strains were grown on iron-limited King's B medium and applied to tomato seeds and soil. Control plants were treated with water. Tertiary leaves were infected with 10 droplets of $4 \mu$ of spore suspension containing $10^{6}$ spores $/ \mathrm{ml}, 0.01 \mathrm{M}$ glucose, and $6.7 \mathrm{mM} \mathrm{KH} \mathrm{HO}_{4}$. Infections were evaluated 4 days after inoculation by counting the number of spreading $B$. cinerea lesions on each leaf. Data represented are means for three experiments, each with 12 leaves per treatment. Statistical analysis by a logistic regression was performed on pooled data, because interaction between experiment and treatment was not significant at $P=0.05$. 
and associates (1988) and Reimmann and associates (1998) that Pch is derived from one molecule of salicylate and two molecules of cysteine. In vitro experiments with 7NSK2 grown on M9 succinate amended with L-cysteine in concentrations ranging from 1 to $100 \mathrm{mg} /$ liter clearly demonstrate that high L-cysteine concentrations in the culture medium result in higher Pch production (Fig. 2). It is not unlikely that cysteine concentrations on the tomato root surface are high enough to favor the conversion of SA to Pch, leaving no detectable amounts of free SA on the root surface.

\section{Importance of SA-dependent defense in resistance induced by KMPCH and 7NSK2.}

$\mathrm{KMPCH}$ produces SA on tomato roots; therefore, the involvement of SA-dependent defense in induced resistance was analyzed. PAL, which was shown to be crucial for activation of SA-dependent defense (Smith-Becker et al. 1998; Pallas et al. 1996), was monitored in control tomato roots and tomato roots colonized by KMPCH and 7NSK2 (Fig. 3). PAL activity in roots of control plants and roots colonized by 7NSK2 was normally distributed and not statistically different. In roots treated with KMPCH, PAL activity was not normally distributed. Colonization of tomato roots by KMPCH increased PAL activity in roots, but only in approximately $50 \%$ of the plants. De Meyer and associates (1999b) observed a similar phenomenon in bean roots colonized by KMPCH.

To study the role of the SA-dependent defense signaling pathway in induced resistance by KMPCH and 7NSK2, transgenic NahG tomato plants, which are unable to accumulate SA, were root inoculated with $\mathrm{KMPCH}$, KMPCH-567, and 7NSK2 and infected with $B$. cinerea. All bacterial strains were unable to induce resistance to $B$. cinerea in $N a h G$ tomato plants (Fig. 4). This result indicates that, although SA is not involved at the induction site of ISR by $7 \mathrm{NSK} 2$, the strain needs a functional SA response to induce resistance against $B$. cinerea.

\section{Pch is necessary, but not sufficient to induce resistance} in tomato.

A SA ${ }^{-}$and $\mathrm{Pch}^{-}$mutant of 7NSK2 (i.e., 7NSK2-562) no longer induced resistance in tomato to $B$. cinerea (Fig. 1); therefore, we verified if Pch was crucial for induction of resistance in tomato to $B$. cinerea. However, the Pch-producing strain $P$. aeruginosa PNA1 that was used for this purpose was unable to induce resistance (data not shown). Apparently, Pch is necessary but not sufficient to induce resistance in tomato to $B$. cinerea. Interestingly, 7NSK2 and PNA1 differ in the production of phenazines. 7NSK2 produces the blue phenazine pigment pyocyanin, while PNA1 produces both phenazine-1carboxylate (PCA) and phenazine-1-carboxamide (PCN) (Anjaiah et al. 1998) and is unable to synthesize pyocyanin. It was shown before that high concentrations of purified pyocyanin can induce resistance to $B$. cinerea in bean (Abeysinge 1999); therefore, we wanted to investigate whether pyocyanin production by 7 NSK2 is involved in induced resistance. For that purpose, we constructed a pyocyanin-negative mutant in $7 \mathrm{NSK} 2$ by miniTnphoA3 mutagenesis. In the white mutant PHZ1, the miniTnphoA3 had inserted at position 4712706 in gene PA4209 (98\% sequence identity), which corresponds to phzM (Mavrodi et al. 2001). The product of this gene is an $O$ methyl transferase, which is necessary for the conversion of PCA to 5-methylphenazine-1-carboxylic acid betaine (Mavrodi et al. 2001).

\section{NSK2 may induce resistance in tomato} through production of pyocyanin and Pch.

The lack of pyocyanin production by PHZ1 was confirmed in in vitro experiments monitoring production of pyocyanin by the wild-type strain 7NSK2, PHZ1, and 7NSK2-562 (Fig. 5). PHZ1 was completely unable to produce pyocyanin whereas 7NSK2-562 appeared to overproduce this phenazine.

In induced resistance infection assays, the pyocyanin-negative mutant PHZ1 was not able to induce resistance in tomato to $B$. cinerea (Fig. 6), indicating that pyocyanin is necessary for 7NSK2 to induce resistance. We applied 7NSK2-562 and PHZ1 together on tomato roots and observed an induction of resistance to a level comparable to that observed in plants colonized by the WT strain 7NSK2 or KMPCH, where PHZ1 $\left(\mathrm{Pch}^{+}, \mathrm{SA}^{+}\right.$, pyocyanin $\left.{ }^{-}\right)$and $7 \mathrm{NSK} 2-562\left(\mathrm{Pch}^{-}, \mathrm{SA}^{-}\right.$, pyocya$\operatorname{nin}^{+}$) alone were not sufficient to induce resistance (Fig. 6). These results indicate that 7NSK2 induces resistance by means of a synergistic action of Pch and pyocyanin, although a role of SA cannot be excluded. How a combined action of Pch and pyocyanin can lead to induced resistance remains to be investigated. However, in mammalian cells it is known that pyocyanin can be redox-cycled, generating $\mathrm{OH}$ radicals in the presence of Fe-Pch. It is not unlikely that a similar mechanism occurs on plant roots and that reactive oxygen species (ROS) are involved in the induction of resistance (Mehdy 1994). Although we analyzed several ROS scavenging enzymes (i.e., peroxidases and catalases), we were unable to detect changes in enzyme activity in roots or leaves upon root colonization by $P$. aeruginosa 7NSK2 (data not shown).

\section{In-trans complementation of PHZ1 \\ for pyocyanin production restores ability \\ to induce resistance in tomato to $B$. cinerea.}

With the aid of the Pseudomonas genome-sequencing project, the complete functional $p h z M$ gene of 7NSK2 was polymerase chain reaction (PCR)-amplified and cloned into pBBR1MCS. The complemented PHZ1-C strain thus obtained induced resistance in tomato to B. cinerea (Fig. 7) to a level

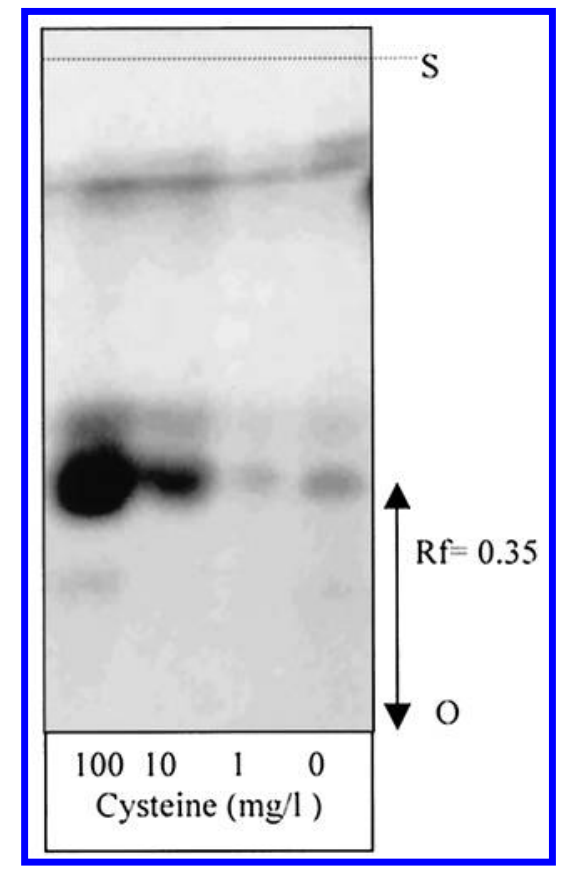

Fig. 2. Effect of L-cysteine added to M9-succinate culture medium on the production of pyochelin by Pseudomonas aeruginosa 7NSK2. L-cysteine was added to the medium in concentrations ranging from 1 to 100 $\mathrm{mg} / \mathrm{liter}$. Pyochelin was extracted from $25 \mathrm{ml}$ of supernatant with ethyl acetate and thin-layer chromatography (TLC) plates were developed in chloroform:acetic acid:ethanol (90:5:2.5) and analyzed under white light after spraying with $2 \mathrm{M} \mathrm{FeCl}_{3}$. Pyochelin migrates on TLC plates with an $R_{\mathrm{f}}$-value of 0.35 to 0.4 (Visca et al. 1993). $\mathrm{O}=$ origin of migration; $\mathrm{S}=$ solvent front. 
comparable with other resistance-inducing strains, such as $\mathrm{KMPCH}$. These results demonstrate unambiguously the necessity of pyocyanin production in the 7NSK2-type of induced resistance.

\section{DISCUSSION}

In the present work, we demonstrate that $P$. aeruginosa $\mathrm{KMPCH}$ induces resistance to $B$. cinerea in tomato. $\mathrm{KMPCH}$ root colonization resulted in increased SA levels on tomato roots; therefore, we suggest that this increase in free SA is attributed to the production of bacterial SA, which apparently stimulates PAL activity in tomato roots. Similar increases in free SA levels were observed on bean roots colonized by $P$. aeruginosa KMPCH (11.5 ng/g of root) (De Meyer et al. $1999 \mathrm{~b}$ ) and on tobacco roots colonized by $P$. fluorescens CHA0 (45.3 ng/plant), a resistance-inducing strain, which produces SA (Maurhofer et al. 1998). It cannot be excluded that increases in free SA on tomato roots colonized by KMPCH are due to in planta SA biosynthesis. De Meyer and associates (1999b), however, demonstrated that nanogram amounts of exogenous SA, applied to bean roots in a hydrophonic system, do not affect basal levels of free SA in bean roots 24 or $48 \mathrm{~h}$ after application, although these low SA amounts do induce PAL-activity.

Surprisingly, the WT strain 7NSK2, which also produces SA in vitro (De Meyer and Höfte 1997), does not produce detectable amounts of SA on tomato root surface and does not induce PAL activity (Fig. 3). However, a functional SA response in the plant is needed to induce resistance because 7NSK2 no longer induced resistance in transgenic $N a h G$ tomato plants in which SA is converted to catechol (Brading et al. 2000). We have shown before that 7NSK2 also is unable to induce resistance to TMV in transgenic NahG tobacco (De Meyer et al. 1999a).

7NSK2 produces SA in vitro (De Meyer and Höfte 1997), whereas in vivo SA production could not be demonstrated. It cannot be excluded that 7NSK2 still produces low levels of SA on tomato roots which cannot be detected with our extraction method. Alternatively, it is possible that SA is efficiently converted to Pch on tomato roots. Pch is derived from one mole- cule of SA and two molecules of cysteine (Ankenbauer et al. 1988; Reimmann et al. 1998). In vitro experiments have shown that Pch production by 7 NSK2 increases in the presence of L-cysteine (Fig. 2). Cysteine is one of the amino acids exudated by tomato roots (Gamliel and Katan 1992), so it is likely that SA is efficiently converted to Pch in the rhizosphere of tomato in the presence of L-cysteine. A similar phenomenon has been described for the biocontrol strain $P$. fluorescens WCS374, which produces the SA-based siderophore pseudomonine (Mercado-Blanco et al. 2001). This bacterium secretes large amounts of SA under iron-limiting conditions in culture. However, this is likely to be an artifact resulting from the lack of substrate (in this case histamine) required for pseudomonine biosynthesis (van Loon et al. 1998). Although we have shown, by using our SA-producing mutant $\mathrm{KMPCH}$, that bacterial SA can induce resistance in various plants, it is possible that this is not an important bacterial determinant in induced resistance in wild-type bacteria that produce SA as a precursor for other siderophores.

7NSK2 root colonization does not lead to detectable amounts of SA on tomato roots, but $\mathrm{SA}^{-}$mutants (which are automatically $\mathrm{Pch}^{-}$) of $7 \mathrm{NSK} 2$ loose their capacity to induce resistance; therefore, we investigated the role of Pch in induced resistance. The Pch-producing rhizobacterial strain $P$. aeruginosa PNA1 (Anjaiah et al. 1998), however, did not induce resistance to $B$. cinerea in tomato. We also were unable to induce resistance in tomato with purified Pch (data not shown). In addition, the mutant PHZ1 (pyocyanin ${ }^{-}$) which still produces SA and Pch lost the ability to induce resistance in tomato to $B$. cinerea. Therefore, we concluded that Pch alone was not sufficient to induce resistance in tomato to $B$. cinerea. PNA1 and PHZ1 differ from 7NSK2 in the production of their phenazine antibiotics. PNA1 produces PCA and PCN and is a strong antagonist of Pythium and Fusarium spp. (Anjaiah et al. 1998; Tambong and Höfte 2001). PNA1, however, is unable to produce pyocyanin, whereas this blue phenazine compound is produced by 7 NSK2. Abeysinghe (1999) has shown that high concentrations of purified pyocyanin $(0.1 \mathrm{mM})$ can induce resistance to $B$. cinerea in bean. Mutant PHZ1 is not able to produce pyocyanin due to an insertion in the phzM gene that encodes an $O$-methyltransferase. In their study, Mavrodi and

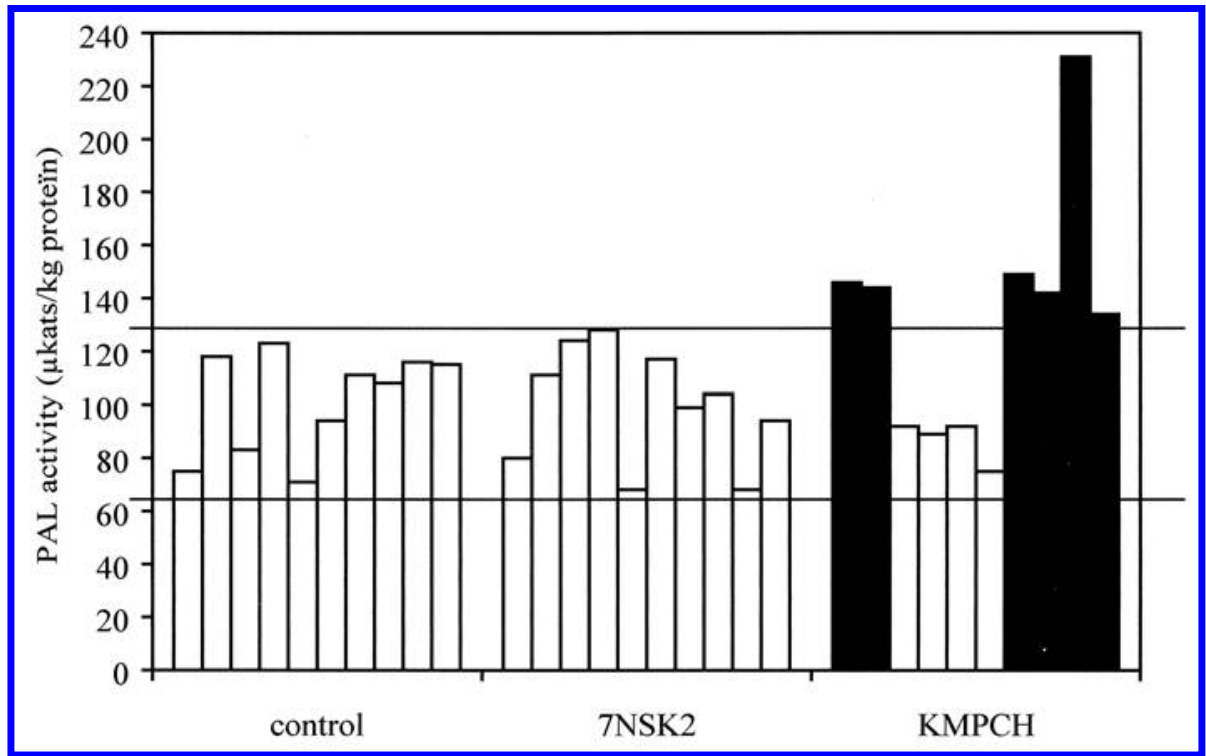

Fig. 3. Phenylalanine ammonia lyase (PAL) activity in roots of 5-week-old soil-grown tomato plants treated with Pseudomonas aeruginosa KMPCH and 7NSK2. Bars represent the average of two experiments, each consisting of five replicates. PAL data of KMPCH-colonized roots were not normally distributed after analysis using the Kolmogorov-Smirnov test. PAL activity was not induced in all KMPCH-treated roots. Horizontal lines represent the 95\% confidence intercept of the normally distributed PAL activity in control roots. Shaded bars exceed the $95 \%$ confidence intercept. 
associates (2001) mentioned the fact that a phzM mutant of PAO1 produces PCA, 1-hydroxyphenazine (1-OH-PHZ), and PCN. Ethyl acetate extracts of the phzM mutant in 7NSK2 revealed the production of PCA and a yellow compound that was not migrating at the same position as PCA or PCN. We are currently investigating whether this compound is 1-OH-PHZ or another phenazine-derivative. It is suggested that, in a $p h z M$ mutant of PAO1, 1-OH-PHZ is formed from PCA via enzymatic synthesis, involving the product of the phzS gene (Mavrodi et al. 2001). PhzS encodes a flavine monooxygenase and probably is responsible for the oxidative decarboxylation of the precursor 5-methylphenazine-1-carboxylate betaine. In the absence of the SAM-dependent methylase PhzM, the conversion of PCA to 5-methylphenazine-1-carboxylate betaine does not take place.

Spectrophotometrical analysis clearly showed no production of pyocyanin by PHZ1. In infection experiments, PHZ1 did not induce resistance in tomato to $B$. cinerea. In addition, the $\mathrm{Pch}^{-}$and $\mathrm{SA}^{-}$mutant 7NSK2-562 did not induce resistance either, although it overproduced pyocyanin. Overproduction of pyocyanin by this strain might be explained by the fact that SA, Pch, and pyocyanin are all produced via the shikimate pathway with chorismate as a precursor (Mavrodi et al. 2001; Serino et al. 1997). When 7NSK2-562 and PHZ1 were applied together on tomato roots, they induced resistance in tomato to $B$. cinerea, indicating that both Pch or SA and pyocyanin are needed in induced resistance by 7NSK2.

An attractive hypothesis for the possible synergistic action of pyocyanin and Pch in induced resistance by $7 \mathrm{NSK} 2$ can come from findings in the infection process of the opportunistic human pathogen $P$. aeruginosa. Pyocyanin is considered to be a pathogenicity factor in the infection process of pulmonary epithelial cells. It can undergo redox-cycling, resulting in the generation of superoxide and $\mathrm{H}_{2} \mathrm{O}_{2}$ (Hassan and Fridovich
1979, 1980; Muller and Sorrell 1997). These ROS are converted to the very reactive $\mathrm{OH}$-radical through the HaberWeiss reaction in the presence of Fe-Pch (Britigan et al. 1997). Ultimately, pyocyanin in the presence of Fe-Pch leads to an inactivation of $\alpha 1$-protease inhibitor, resulting in higher human neutrophil elastase activity, contributing to the progress of lung inflammation in cystic fibrosis patients (Britigan et al. 1999). ROS also are important in plants where they play a role in the activation of plant defense mechanisms (Mehdy 1994).

Abeysinghe (1999) has shown that it is possible to generate ROS in bean leaves when pyocyanin was fed to the leaf petiole. However, the amount of pyocyanin produced by 7 NSK2 and 7NSK2-562 on tomato roots (which is in the nanogram range) probably is not sufficiently high to generate ROS by itself. It is possible, however, that pyocyanin and Fe-Pch act synergistically on tomato roots producing the very reactive $\mathrm{OH}$-radical, which in turn triggers induced resistance. Upon root colonization with $7 \mathrm{NSK} 2$, however, we could not observe changes in peroxidase or catalase. It is possible that changes in ROS are just too small to affect the activity of ROS-associated enzymes, or changes are localized in specific cells or on specific sites on the root surface and not present ubiquitously.

We showed that the $P$. aeruginosa strain PNA1 (which produces SA, Pch, and the phenazine compounds PCA and PCN) and the 7NSK2-derived mutant PHZ1 (which is still able to produce SA, Pch, PCA, and an unidentified yellow phenazinecompound) are not able to induce resistance. Various phenazine compounds, including PCA and 1-OH-PHZ, are known to be redox active (Kerr 2000; Muller 1995). However, it is possible that the ability to reduce molecular oxygen to superoxide is unique for pyocyanin. Muller (1995) showed that 1-OH-PHZ is unable to reduce molecular oxygen to superoxide but, to our knowledge, this has not been investigated for PCA. In addition, it has been shown that pyocyanin, but not 1-

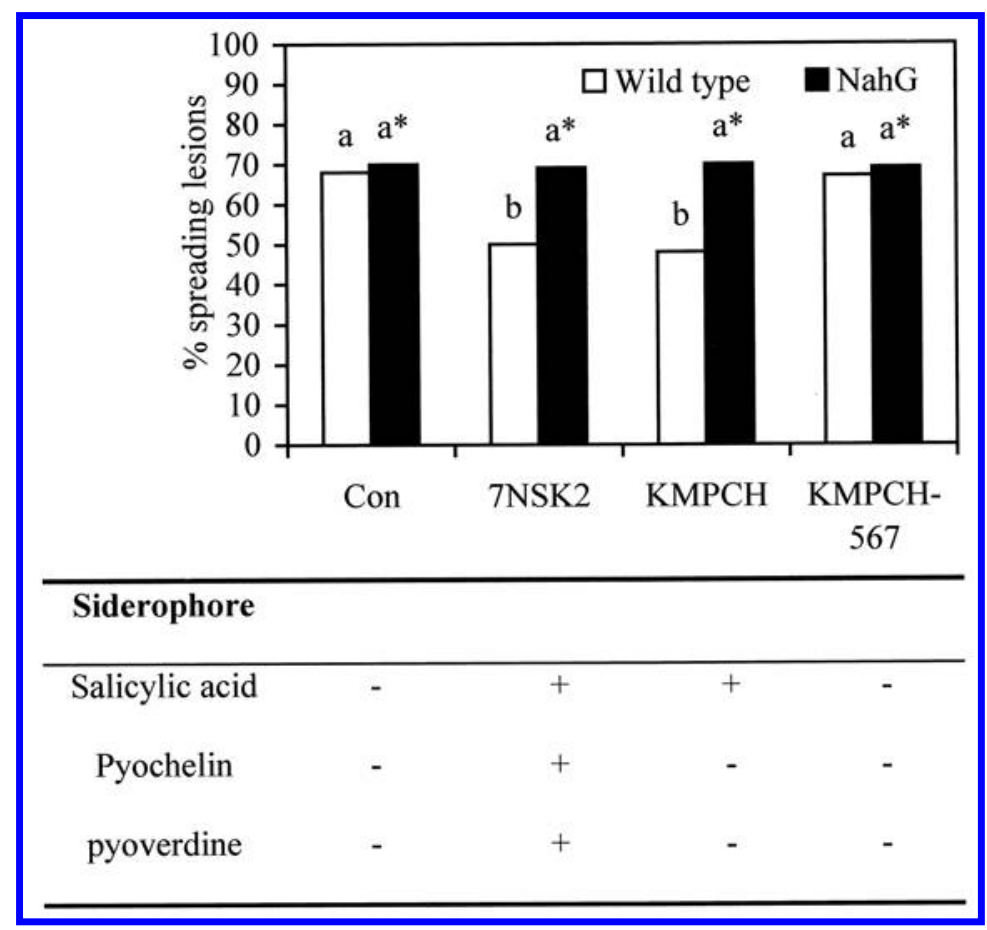

Fig. 4. Induced resistance by Pseudomonas aeruginosa 7NSK2 and its siderophore mutants in wild-type and NahG tomato plants, containing the bacterial salicylic acid (SA) hydroxylase converting SA to catechol. Plants were grown under greenhouse conditions at $24 \pm 3^{\circ} \mathrm{C}$. All strains were grown on ironlimited King's B medium and control plants were treated with water. Tertiary leaves were infected with 10 droplets of $4 \mu$ of spore suspension containing

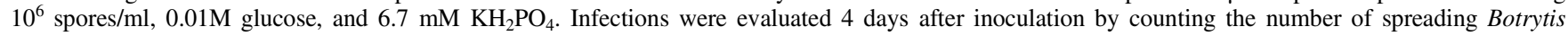
cinerea lesions on each leaf. Data represented are means for three experiments each with 12 leaves per treatment. Infection was evaluated 4 days after infection by counting the number of spreading lesions. Statistical analysis by a logistic regression was performed on pooled data, because interaction between experiment and treatment was not significant at $P=0.05$. 
$\mathrm{OH}-\mathrm{PHZ}$, increased the rate and duration of oxygen uptake by neutrophils (Ras et al. 1990). In the same study, the authors also mentioned other differences in the proinflammatory interactions of 1-OH-PHZ and pyocyanin with human phagocytes. It is not unlikely that the generation of ROS by the Fe-Pch-pyocyanin interaction is the basis for induced resistance by 7NSK2.

\section{MATERIALS AND METHODS}

Bacterial strains, growth conditions, and plasmids.

The bacterial strains used in this study are listed in Table 1 . For mutation and cloning experiments, P. aeruginosa and Escherichia coli strains were grown overnight at $37^{\circ} \mathrm{C}$ in liquid

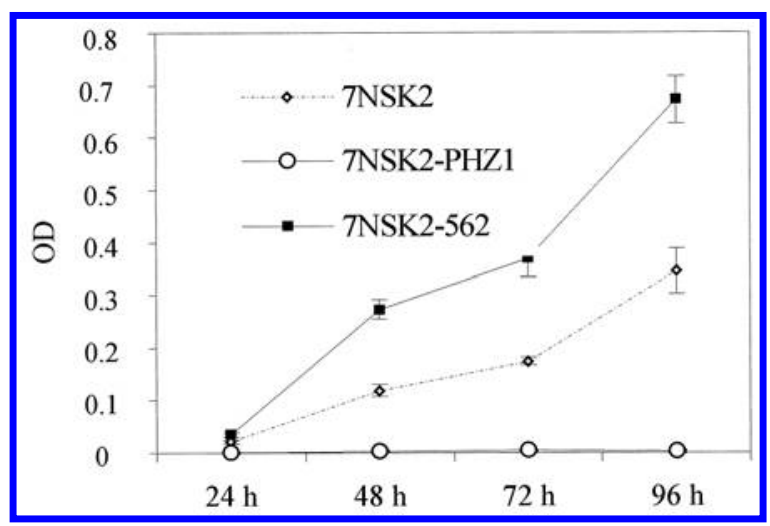

Fig. 5. In vitro production of pyocyanin by Pseudomonas aeruginosa 7NSK2, 7NSK2-562, and the pyocyanin-negative mutant PHZ1 determined spectrophotometrically at $510 \mathrm{~nm}$ in the presence of $\mathrm{HCl}$. Production was monitored at $24,48,72$, and $96 \mathrm{~h}$ after inoculation. Results are the mean of two experiments, each consisting of three replicates. or solid Luria-Bertani medium (LB) (Miller 1972). P. aeruginosa strains were differentiated from $E$. coli on solid CAA medium (Difco Laboratories, Detroit), on which $P$. aeruginosa strains produce fluorescent yellow colonies due to the production of pyoverdine. Pyocyanin production of the different $P$. aeruginosa strains was observed as a diffusing deep-blue color in Pseudomonas $\mathrm{P}$ broth or solid Pseudomonas $\mathrm{P}$ agar (Difco Laboratories) at $28^{\circ} \mathrm{C}$. For inoculation experiments on tomato plants, $P$. aeruginosa was grown overnight on iron-limiting King's B (KB) medium (King et al. 1954) at $37^{\circ} \mathrm{C}$.

$\mathrm{X}$-gal was used at a concentration of $40 \mu \mathrm{g} / \mathrm{ml}$ and IPTG (isopropyl- $\beta$-D-thiogalactoside) at a concentration of $100 \mathrm{mM}$. Antibiotics were added at the following concentrations: ampicillin $(100 \mu \mathrm{g} / \mathrm{ml})$, chloramphenicol $(25 \mu \mathrm{g} / \mathrm{ml}$ for $E$. coli and 200 $\mu \mathrm{g} / \mathrm{ml}$ for $P$. aeruginosa), tetracycline $(15 \mu \mathrm{g} / \mathrm{ml})$, gentamicin (20 $\mu \mathrm{g} / \mathrm{ml}$ for $E$. coli and $100 \mu \mathrm{g} / \mathrm{ml}$ for $P$. aeruginosa), and spectinomycin $(50 \mu \mathrm{g} / \mathrm{ml})$, unless otherwise stated.

Mobilization of plasmids from $E$. coli to $P$. aeruginosa was done by spreading $0.1 \mathrm{ml}$ of saturated cultures in LB medium of donor and recipient on solid LB and incubating overnight at $37^{\circ} \mathrm{C}$.

\section{Construction of a pyocyanin-negative mutant in $P$. aeruginosa $7 \mathrm{NSK} 2$.}

MiniTnphoA3 was constructed from miniTnphoA2 (Pattery et al. 1999) by replacing the kanamycin cassette at the NotI site with a gentamicin resistance cassette. The gentamicin cassette used for construction of miniTnphoA3 was obtained as a NotI fragment (803 bp) from pGM (C. Baysse, personal communication).

Mutagenesis of the wild type 7NSK2 $P$. aeruginosa strain was carried out by mobilization of the suicide vector pUTminiTnphoA2 from E. coli S17-1( $\lambda$ pir). Transconjugants

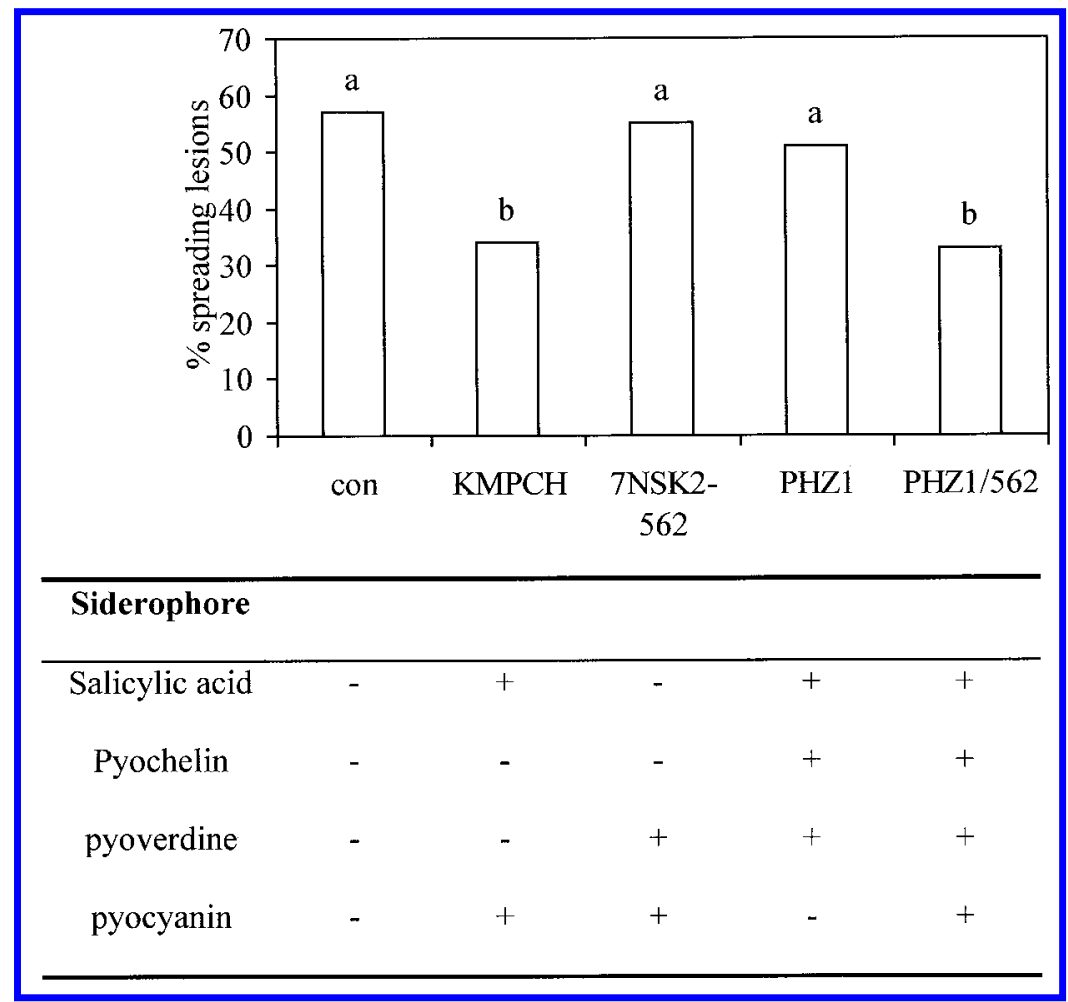

Fig. 6. Influence of tomato root treatment with Pseudomonas aeruginosa 7NSK2, PHZ1, 7NSK2-562, and a combined application of 7NSK2-562 and PHZ1 on the percentage of spreading Botrytis cinerea lesions on tomato leaves. All strains were grown on iron-limited King's B medium and control plants were treated with water. Tertiary leaves were infected with 10 droplets of $4 \mu \mathrm{l}$ of spore suspension containing $10^{6} \mathrm{spores} / \mathrm{ml}$, $0.01 \mathrm{M}$ glucose, and $6.7 \mathrm{mM}$ $\mathrm{KH}_{2} \mathrm{PO}_{4}$. Infections were evaluated 4 days after inoculation by counting the number of spreading $B$. cinerea lesions on each leaf. Data represented are means for three experiments each with 12 leaves per treatment. Statistical analysis by a logistic regression was performed on pooled data, because interaction between experiment and treatment was not significant at $P=0.05$. 
initially were selected on solid CAA medium with gentamicin and tetracycline in order to counterselect the E. coli strain (Cornelis et al. 1992). All mutants were then individually toothpicked into microtiter wells that contained solid P-agar with gentamicin. This facilitated the identification of whitecolored mutants that failed to produce any pyocyanin from the pyocyanin producers (blue-colored) because there was no diffusion of the pigment. A total of three white mutants were obtained, out of which one was found to be completely white (PHZ1), while the other two (PHZ2 and PHZ3) produced traces of pyocyanin (light-blue) after 2 days.

\section{Molecular characterization of PHZ1 and in trans complementation of PHZ1 for pyocyanin production.}

The DNA sequence adjacent to the miniTnphoA3 insertion in PHZ1 was isolated by inverse PCR (IPCR). PCRs and IPCRs were performed either with ExTaq enzyme (Takara) or Proofstart DNA polymerase (Qiagen, Leusden, The Netherlands). Isolation of total DNA from $P$. aeruginosa strains was carried out as described by Wilson (1990). Elution of DNA fragments from $0.8 \%$ agarose gels was carried out using the Qiaquick gel extraction kit (Qiagen).

Total DNA of 7NSK2 and PHZ1 was digested with SmaI and ligated under conditions favoring intramolecular circularization. Amplification of the ligation mixture was carried out using the primer pair PhoA5 (5'-GCGGCAGTCTGATCACCCGTTA-3') located at position 443-422 (Chang et al. 1986) and Gm1 (5'-TGGACCAGTTGCGTGAGCGCATA-3'). Reamplification of the IPCR fragment using nested primers PhoA4 (5'-GCACCGCCGGGTGCAGTAATAT-3') located at position 413-392 (Chang et al. 1986) and Gm2 (5'-TGTCAACTGGGTTCGTGCCTTC-3') showed a 1-kb amplified fragment for strain PHZ1, while the control 7NSK2 showed no amplification. Subsequently, the PCR-amplified product was cloned into pCR2.1 using the TA cloning kit (Invitrogen, Merelbeke, Belgium). The resulting plasmid pMI1 was completely sequenced. The Pseudomonas DNA and protein database was searched for similarities and also for obtaining the complete sequence of $p h z \mathrm{M}$ (PA4209) and phzS (PA4217).

The complete functional $p h z \mathrm{M}$ gene of $7 \mathrm{NSK} 2$ was PCRamplified along with the surrounding flanking sequences using the primers 4209A (5'-CGGCAACGCGCTCAACCAACT-3') and 4209B (5'-TCGAGGGGTGTTTCCCTGTAC-3') which correspond to positions 4711777-4711797 and 47138294713809 on the Pseudomonas genome sequencing project. A fragment of 2,054 bp was obtained which was subsequently cloned blunt into the broad-host range vector $\mathrm{pBBR} 1 \mathrm{MCS}$ at the EcoRV site to yield pPHZM.

This plasmid was mobilized from $E$. coli $\mathrm{S} 17-1(\lambda$ pir $)$ into PHZ1 by conjugation and the transconjugants were selected on solid CAA medium containing chloramphenicol and tetracycline. In order to observe pyocyanin production, 50 transconjugants were toothpicked onto gridded solid P-agar plates containing chloramphenicol. All the clones (PHZ1-C) turned deep blue, indicating that the mutation in strain PHZ1 was indeed complemented in trans. These findings are in accordance with Mavrodi and associates (2001).

\section{Plant material and assay for induced resistance.}

Experiments were performed with tomato plants (Lycopersicon esculentum Mill. cv. Moneymaker) and corresponding transgenic NahG plants in which SA is converted to catechol (Brading et al. 2000). Plants were grown under nonsterile greenhouse conditions in potting soil (Klasmann, substrat no 4, Otrebusy, Germany). The bacterial inoculum for root colonization was prepared from KB plates. The bacteria were washed from the plates with physiological solution and added to the soil in a concentration of $10^{7}$ bacteria per gram of soil.

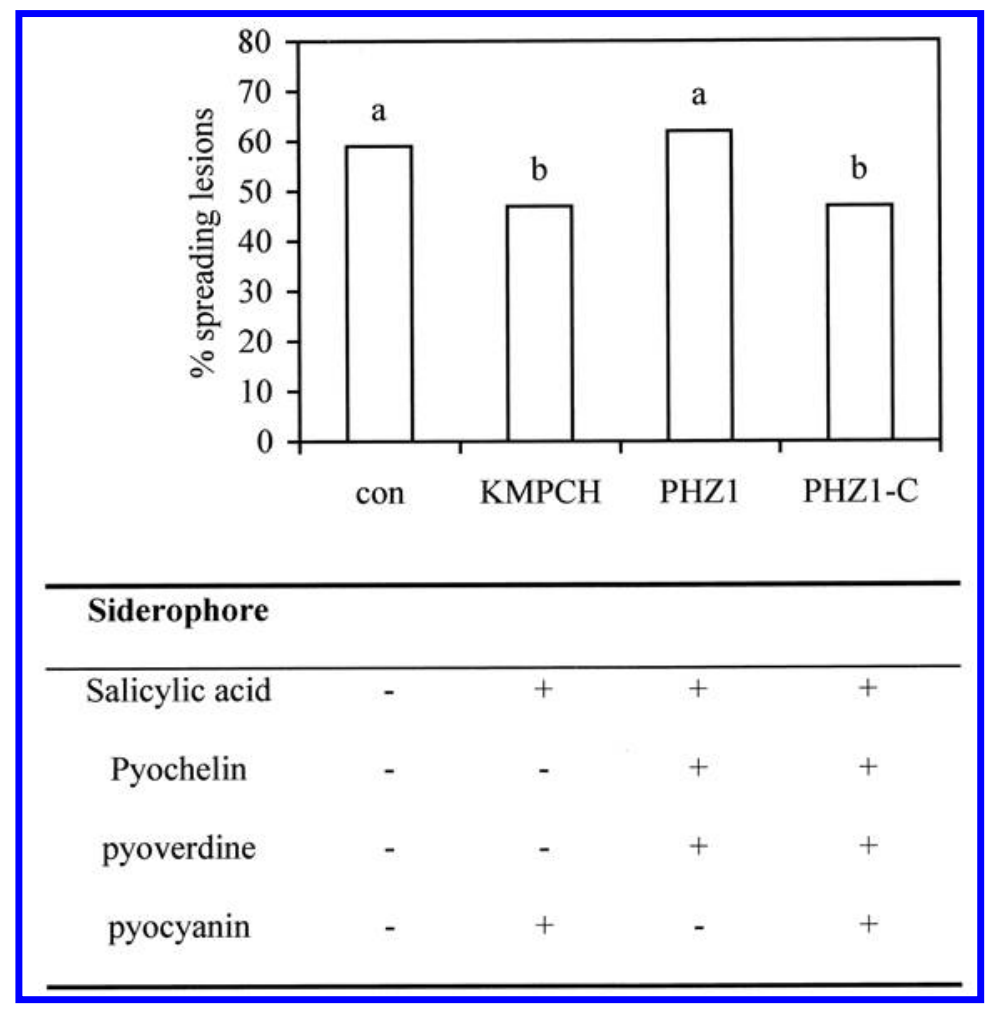

Fig. 7. Influence of complemented pyocyanin production in Pseudomonas aeruginosa PHZ1 on induced resistance in tomato to Botrytis cinerea. All strains were grown on iron-limited King's B medium and control plants were treated with water. Tertiary leaves were infected with 10 droplets of $4 \mu \mathrm{l}$ of spore suspension containing $10^{6}$ spores $/ \mathrm{ml}, 0.01 \mathrm{M}$ glucose, and $6.7 \mathrm{mM} \mathrm{KH}_{2} \mathrm{PO}_{4}$. Infections were evaluated 4 days after inoculation by counting the number of spreading $B$. cinerea lesions on each leaf. Data represented are means for three experiments each with 12 leaves per treatment. Statistical analysis by a logistic regression was performed on pooled data, because interaction between experiment and treatment was not significant at $P=0.05$. 
Table 1. Plasmids and bacteria used in this study with their relevant characteristics

\begin{tabular}{|c|c|c|}
\hline Strains or plasmids & Relevant characteristics $^{\text {a }}$ & Reference or source \\
\hline \multicolumn{3}{|c|}{ Pseudomonas aeruginosa } \\
\hline 7NSK2 & $\mathrm{Pvd}^{+}, \mathrm{Pch}^{+}, \mathrm{SA}^{+}$, wild type & Iswandi et al. 1987 \\
\hline MPFM1 & Tn 5 mutant of $7 \mathrm{NSK} 2, \mathrm{Pvd}^{-}, \mathrm{Pch}^{+}, \mathrm{SA}^{+}$ & Höfte et al. 1991 \\
\hline $\mathrm{KMPCH}$ & $\mathrm{Pvd}^{-}, \mathrm{Pch}^{-}, \mathrm{SA}^{+}$, Chemical mutant of MPFM1; $\mathrm{Km}^{\mathrm{r}}$ & Höfte et al. 1993 \\
\hline 7NSK2-562 & $\mathrm{Pvd}^{+}, \mathrm{Pch}^{-}, \mathrm{SA}^{-}, p c h A$ replacement mutant of $7 \mathrm{NSK} 2$ & De Meyer et al. $1999 b$ \\
\hline MPFM1-569 & $\mathrm{Pvd}^{-}, \mathrm{Pch}^{-}, \mathrm{SA}^{-}$, pchA replacement mutant of MPFM1 & De Meyer and Höfte 1997 \\
\hline KMPCH-567 & $\mathrm{Pvd}^{-}, \mathrm{Pch}^{-}, \mathrm{SA}^{-}, p c h A$ replacement mutant of $\mathrm{KMPCH} ; \mathrm{Km}^{\mathrm{r}}$ & De Meyer et al. $1999 b$ \\
\hline PHZ1 & 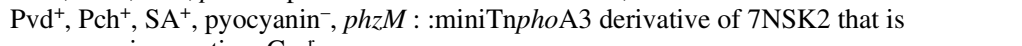 & \\
\hline PHZ1-C & $\begin{array}{l}\text { pyocyanin negative, } \mathrm{Gm}^{\mathrm{r}} \\
\mathrm{Pvd}^{+}, \mathrm{Pch}^{+}, \mathrm{SA}^{+}, \mathrm{PHZ1} \text { containing } \mathrm{pHZM} \text { (functional phzM gene on plasmid } \\
\text { pBBR1MCS) that restores pyocyanin production, } \mathrm{Gm}^{\mathrm{r}}, \mathrm{Cm}^{\mathrm{r}}\end{array}$ & $\begin{array}{l}\text { This work } \\
\text { This work }\end{array}$ \\
\hline PNA1 & $\mathrm{Pvd}^{+}, \mathrm{Pch}^{+}, \mathrm{SA}^{+}$, produces phenazine-1-carboxylate $(\mathrm{PCA})$, wild type & Anjaiah et al. 1998 \\
\hline \multicolumn{3}{|l|}{ Escherichia coli } \\
\hline DH5 $\alpha$ & endA1 hsdR17 supE44 thi-1 recA1 gyrA1 $\Delta($ lac $\mathrm{IZA}-\operatorname{arg\mathrm {F}}) \mathrm{U} 169$ deo $\mathrm{R}$ & Woodcock et al. 1989 \\
\hline GJ23 & $\mathrm{JC} 2692(\mathrm{pGJ} 28)(\mathrm{R} 64 d r d 11), \mathrm{Km}^{\mathrm{r}} / \mathrm{Sm}^{\mathrm{r}} / \mathrm{Tc}^{\mathrm{r}}$ & Van Haute et al. 1983 \\
\hline $\mathrm{S} 17-1(\lambda p i r)$ & thi pro hsd $\mathrm{R}$ recA::RP4-2-Tc ${ }^{\mathrm{r}}:: \mathrm{Mu} \mathrm{Km}^{\mathrm{r}}:: \mathrm{Tn} 7\left(\lambda\right.$ pir), $\mathrm{Sm}^{\mathrm{r}}$ & Simon et al. 1983 \\
\hline \multicolumn{3}{|c|}{ 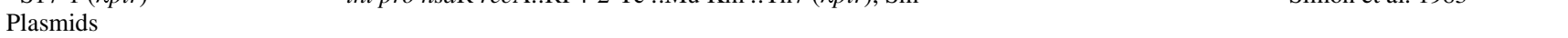 } \\
\hline pUTminiTnphoA3 & MiniTnphoA3 in pUT, $\mathrm{Gm}^{\mathrm{r}} / \mathrm{Cb}^{\mathrm{r}}$, Derivative of miniTn $P h o A$ & Pattery et al. 1999 \\
\hline pUC19 & Cloning and sequencing vector, $\mathrm{Cb}^{\mathrm{r}}$ & Yanisch-Perron et al. 1985 \\
\hline pCR2.1 & TA cloning vector, $\mathrm{Cb}^{\mathrm{r}} / \mathrm{Km}^{\mathrm{r}}$ & Invitrogen \\
\hline pBBR1MCS & Broad host-range cloning vector for Pseudomonas, $\mathrm{Cm}^{\mathrm{r}}$ & Kovach et al. 1994 \\
\hline pBR325 & Suicide vector in Pseudomonas, $\mathrm{Cm}^{\mathrm{r}} / \mathrm{Cb}^{\mathrm{r}} / \mathrm{Tc}^{\mathrm{r}}$ & Bolivar 1978 \\
\hline pMI1 & 1-kb SmaI IPCR fragment of PHZ1 in pCR2.1, $\mathrm{Cb}^{\mathrm{r}} / \mathrm{Km}^{\mathrm{r}}$ & This work \\
\hline pHZM & $\begin{array}{l}\text { A 2,054-bp PCR-amplified fragment of primer pair 4209A-B }(p h z \mathrm{M}) \text { of } 7 \mathrm{NSK} 2 \text { cloned in } \\
\text { the EcoRV site of pBBR1MCS, Cm }{ }^{\mathrm{r}}\end{array}$ & This work \\
\hline
\end{tabular}
${ }^{a}$ Pvd $=$ Pyoverdine, $\mathrm{Pch}=$ Pyochelin, $\mathrm{SA}=$ Salicylic acid, $\mathrm{Km}=$ Kanamycin, $\mathrm{Gm}=$ Gentamicin; $\mathrm{Tc}=\mathrm{Tetracycline} ; \mathrm{Cm}=\mathrm{Chloramphenicol}, \mathrm{Cb}=$
Carbenicilin, $\mathrm{Sm}=$ Spectinomycin, $\mathrm{IPCR}=$ inverse polymerase chain reaction.

In addition, seeds were dipped prior to sowing in a bacterial suspension of $10^{7}$ bacteria per $\mathrm{ml}$ of water. After 10 days, seedlings were transplanted and grown for 4 weeks under greenhouse conditions $\left(24^{\circ} \mathrm{C} \pm 3\right)$. Four weeks after seedling transfer, plants were infected with $B$. cinerea R16 (Faretra and Pollastro 1991) in a detached leaf assay as described by Audenaert and associates (2002). Each tertiary leaf composed of five leaflets was inoculated with $104-\mu$ drops of a suspension of $10^{6} \mathrm{~B}$. cinerea spores per $\mathrm{ml}$, obtained as previously described (Audenaert et

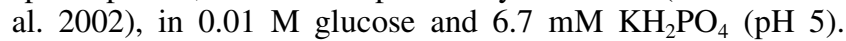
Each experiment was carried out three times and contained 12 infected leaves per treatment. Four days after inoculation, $B$. cinerea infections were scored as a spreading lesion if the fungus had developed beyond the inoculum drop. Results were categorized in a dichotomous variable (spreading or nonspreading) and analyzed by logistic regression analysis (Agresti 1990). Data for experiments with the same set-up were pooled for statistical analysis if a two-way analysis of variance (ANOVA) revealed that interaction between treatment and experiment was not significant at $P=0.05$.

\section{Enzymatic assay.}

PAL activity was determined in roots of 5 week-old tomato plants as described by Edwards and Kessmann (1992) and Audenaert and associates (2002). Roots were ground in liquid $\mathrm{N}_{2}$ and extracted with $50 \mathrm{mM}$ Tris- $\mathrm{HCl}$ ( $\mathrm{pH}$ 8.5). Five plants per treatment were analyzed and experiments were repeated two times. Results were statistically analyzed by ANOVA and means were compared with a post hoc Duncan test at $P=0.05$.

\section{Determination of SA on roots of tomato plants.}

Free SA and bound SA was measured as described by Meuwly and Métraux (1993) with $O$-anisic acid as an internal standard. Samples were taken from control roots and roots colonized by bacteria, 4 weeks after seedling transfer. Each sample consisted of $2.5 \mathrm{~g}$ of root material pooled from five individual plants. Five samples were taken per treatment. Results were statistically analyzed by ANOVA and means were compared with a post hoc Duncan test at $P=0.05$.
In vitro production of SA, pyocyanin, and Pch by bacterial strains.

To monitor in vitro production of pyocyanin by the distinct strains, bacteria were grown for $96 \mathrm{~h}$ in 100-ml Erlenmeyers containing $25 \mathrm{ml}$ of Pseudomonas $P$ broth at $28^{\circ} \mathrm{C}$. Pyocyanin present in the supernatant was extracted twice with chloroform and determined spectrophotometrically in the presence of 0.1 $\mathrm{M} \mathrm{HCl}$ (optical density at $510 \mathrm{~nm}$ ) as described by Essar and associates (1990). This experiment was set up in three replicates.

To determine SA and Pch production in the presence of Lcysteine, bacteria were grown in 100-ml Erlenmeyer flasks containing $25 \mathrm{ml}$ of M9 succinate medium (Anjaiah et al. 1998) with L-cysteine at 0, 1, 10, and $100 \mathrm{mg}$ per liter (Sigma, Bornem, Belgium) and were put for 2 days at $28^{\circ} \mathrm{C}$ and 150 $\mathrm{rpm}$. Bacterial cultures were centrifuged and the supernatant was adjusted to $\mathrm{pH}$ 1.5. Supernatant was extracted twice with ethylacetate and organic layers were dried under vacuum. Pellets were dissolved in $20 \mu \mathrm{l}$ of methanol and were spotted on a thin-layer chromatography (TLC) plate that was developed in chloroform:acetic acid:ethanol (90:5:2.5) as solvent (Visca et al. 1993). TLC plates were analyzed under UV light and under white light after spraying with $2 \mathrm{M} \mathrm{FeCl}_{3}$ dissolved in $0.1 \mathrm{M}$ $\mathrm{HCl}$.

\section{ACKNOWLEDGMENTS}

This project was supported by a specialization fellowship of the Flemish Institute for the Stimulation of Scientific-Technological Research in Industry (IWT, Belgium) given to K. Audenaert and by a grant from the Fund for Scientific Research-Flanders (FWO, Belgium). We thank J. Jones for providing NahG tomato seeds, A. Buchala for carrying out the SA-determinations, and I. Delaere and A. Van Damme for their technical assistance and help during the plant experiments.

\section{LITERATURE CITED}

Abeysinghe, S. 1999. Investigation of metabolites of the rhizobacterium Pseudomonas aeruginosa strain SA44 involved in plant protection, Ph.D. thesis, Vrije Universiteit Brussel.

Agresti, A. 1990. Categorical data analysis. Wiley and Sons, New York. 
Anjaiah, V., Koedam, N., Nowak-Thompson, B., Loper, J. E., Höfte, M., Tambong, J. T., and Cornelis, P. 1998. Involvement of phenazines and anthranilate in the antagonism of Pseudomonas aeruginosa PNA1 and Tn5-derivatives towards Fusarium sp. And Pythium sp. Mol. PlantMicrobe Interact. 11:847-854.

Ankenbauer, R. G., Toyokuni, T., Staley, A., Rinehart, K. L., and Cox, C. D. 1988. Synthesis and biological activity of pyochelin, a siderophore of Pseudomonas aeruginosa. J. Bacteriol. 170:5364-5367.

Audenaert, K., De Meyer, G., and Höfte, M. 2002 Abscisic acid determines basal susceptibility of tomato to Botrytis cinerea and suppresses salicylic acid-dependent signaling mechanisms. Plant Physiol. 128:491501.

Bigirimana, J., and Höfte, M. 2002. Induction of systemic resistance to Colletotrichum lindemuthianum in bean by a benzothiadiazole derivative and rhizobacteria. Phytoparasitica 30:159-168.

Bolivar, F. 1978. Construction and characterization of new cloning vehicles. III. Derivatives of plasmid pBR322 carrying unique EcoRI sites for selection of EcoRI generated recombinant DNA molecules. Gene 4:121-136.

Brading, P. A., Hammond-Kosack, K. E., Parr, A., and Jones, J. D. G. 2000. Salicylic acid is not required for Cf-2 and Cf-9-dependent resistance of tomato to Cladosporium fulvum. Plant J. 23:305-318.

Britigan, B. E., Railsbeck, M. A., and Cox, C. D. 1999. The Pseudomonas aeruginosa secretory product pyocyanin inactivates $\alpha 1$-protease inhibitor: Implication for the pathogenesis of cystic fibrosis lung disease. Infect. Immun. 67:1207-1212.

Britigan, B. E., Rasmussen, G. T., and Cox, C. D. 1997. Augmentation of oxidant injury to human pulmonary epithelial cells by the Pseudomonas aeruginosa siderophore pyochelin. Infect. Immun. 65:1071-1076.

Britigan, B. E., Roeder, T. L., Rasmussen, G. T., Shasby, D. M., McCormick, M. L., and Cox, C. D. 1992. Interaction of the Pseudomonas aeruginosa secretory products pyocyanin and pyochelin generates hydroxyl radicals and causes synergistic damage to endothelial cells: Implications for Pseudomonas associated tissue. J. Clin. Invest. 90:21872196.

Chang, C. N., Kuang, W. T., and Chen E. Y. 1986. Nucleotide sequence of the alkaline phosphatase gene of Escherichia coli. Gene 44:121-125.

-Chipperfield, J. R., and Ratledge, C. 2000. Salicylic acid is not a bacterial siderophore: A theoretical study. Biometals 13:165-168.

Cornelis, P., Anjaiah, V., Koedam, N., Delfosse, P., Jacques, P., Thonart, P., and Neirinckx, L. 1992. Stability, frequency and multiplicity of transposon insertions in the pyoverdine region in the chromosomes of different fluorescent pseudomonads. J. Gen. Microbiol. 138:1337-1343.

De Meyer, G., Audenaert, K., and Höfte, M. 1999a. Pseudomonas aeruginosa 7NSK2-induced systemic resistance in tobacco depends on in planta salicylic acid but is not associated with PR1a gene-expression. Eur. J. Plant Pathol. 105:513-517.

De Meyer, G., Capiau, K., Audenaert, K., Buchala, A., Métraux, J.-P., and Höfte, M. 1999b. Nanogram amounts of salicylic acid produced by the rhizobacterium Pseudomonas aeruginosa 7NSK2 activate the systemic acquired resistance pathway on bean. Mol. Plant-Microbe Interact. 12:450-459.

De Meyer, G., and Höfte, M. 1997. Salicylic acid produced by the rhizobacterium Pseudomonas aeruginosa 7NSK2 induces resistance to leaf infection by Botrytis cinerea in bean. Phytopathology 87:588-593.

Edwards, R., and Kessmann, H. 1992. Isoflavonoid phytoalexins and their biosynthetic enzymes. Pages 45-62 in: Molecular Plant Pathology: A Practical Approach, Vol. 2. S. Gurr, M. McPherson, and D. Bowles, eds. Oxford University Press, Oxford, U.K.

Essar, D. W. Eberly, L., Hadero, A., and Strange, R. N. 1990. Identification and characterization of genes for a second anthranilate synthase in Pseudomonas aeruginosa: Interchangeability of the two anthranilate synthases and evolutionary implication. J. Bacteriol. 172:884-900.

Faretra, F., and Pollastro, S. 1991. Genetic bases of resistance to benzimidazole and dicarboximide fungicides in Botryotinia fuckeliana (Botrytis cinerea). Mycol. Res. 8:943-951.

Gamliel, J., and Katan, A. 1992. Influence of seed and root exudates on fluorescent pseudomonads and fungi in solarized soil. Phytopathology 82:320-327.

Hassan, H. M., and Fridovich, I. 1979. Intracellular production of superoxide radical and hydrogen peroxide by redox-active compounds. Arch. Biochem. Biophys. 196:385-395.

Hassan, H. M., and Fridovich, I. 1980. Mechanism of the antibiotic action of pyocyanin. J. Bacteriol. 141:156-163.

Höfte, M., Buysens, S., Koedam, N., and Cornelis, P. 1993. Zinc affects siderophore-mediated high affinity iron uptake systems in the rhizosphere Pseudomonas aeruginosa 7NSK2. Biometals 6:85-91.

Höfte, M., Seong, K. Y., Jurkevitch, E., and Verstraete, W. 1991. Pyoverdine production by the plant growth beneficial Pseudomonas strain 7NSK2: Ecological significance in soil. Pages 289-297 in: Iron Nutri- tion and Interactions in Plants. Kluwer Academic Publishers, Dordrecht, The Netherlands.

-Iswandi, A., Bossier, P., Vandenabeele, J., and Verstraete, W. 1987. Effect of seed inoculation with the rhizopseudomonas strain 7NSK2 on the root microbiota of maize (Zea mays) and barley (Hordeum vulgare). Biol. Fertil. Soils 3:153-158.

Kerr, J. R. 2000 Phenazine pigments: Antibiotics and virulence factors. Infect. Dis. Rev. 2:184-194.

King, E. O., Ward, M. K., and Raney, D. E. 1954. Two simple media for demonstration of pyocyanin and fluorescin. J. Lab. Clin. Med. 44:301307.

Kovach, M. E., Phillips, R. W., Elzer, P. H., Roop, R. M., and Peterson, K. M. 1994. PBBR1MCS: A broad-host-range cloning vector. Biotechniques 16:800-802.

Leeman, M., den Ouden, F. M., van Pelt, J. A., Dirkx, F. P. M., Steijl, H., Bakker, P. A. H. M., and Schippers, B. 1996. Iron availability affects induction of systemic resistance to Fusarium wilt of radish by Pseudomonas fluorescens. Phytopathology 86:149-155.

-Maurhofer, M., Hase, C., Meuwly, P., Métraux, J.-P. and Défago, G.1994. Induction of systemic resistance of tobacco to tobacco necrosis virus by the root-colonizing Pseudomonas fluorescens strain CHAO: Influence of gacA and of pyoverdine production. Phytopathology 84:139-146.

-Maurhofer, M., Reimmann, C., Schmidli-Sacherer, P., Heeb, S., Haas, D., and Défago, G. 1998. Salicylic acid biosynthetic genes expressed in Pseudomonas fluorescens strain P3 improve the induction of systemic resistance in tobacco against tobacco necrosis virus. Phytopathology 88:678-684.

Mavrodi, D. V., Bonsall, R. F., Delaney, S. M., Soule, M. J., Phillips, G., and Thomashow, L. S. 2001. Functional analysis of genes for biosynthesis of pyocyanin and phenazine-1-carboxamide from Pseudomonas aeruginosa PAO1. J. Bacteriol. 183:6454-6465.

Mehdy, M. C. 1994. Active oxygen species in plant defense against pathogens. Plant Physiol. 105:467-472.

Mercado-Blanco, J., van der Drift, K. M. G. M., Olsson, P. E. Oates, T. J. E., van Loon L. C., and Bakker P. A. H. M. 2001. Analysis of the pmsCEAB gene cluster involved in the biosynthesis of salicylic acid and the siderophore pseudomonine in the biocontrol strain Pseudomonas fluorescens WCS374. J. Bacteriol. 183:1909-1920.

Meuwly, P., and Métraux, J.-P. 1993. Ortho-anisic acid as internal standard for the simultaneous quantitation of salicylic acid and its putative biosynthetic precursors in cucumber leaves. Anal. Biochem. 214:500-505.

Miller, J. H. 1972. Experiments in Molecular Genetics.: Cold Spring Harbor Laboratory Press, Cold Spring Harbor, NY, U.S.A.

Muller, M. 1995. Scavenging neutrophil-derived superoxide anion by 1hydroxyphenazine, a phenazine derivative associated with chronic Pseudomonas aeruginosa infection: Relevance to cystic fibrosis. Biochim. Physica Acta-Mol. Basis Dis. 1272:185-189.

Muller, M., and Sorrell, T. 1997. Modulation of neutrophil superoxide response and intracellular diacylglyceride levels by the bacterial pigment pyocyanin. Infect. Immun. 65:2483-2487.

Pallas, J., Paiva, N., Lamb, C., and Dixon, R. 1996. Tobacco plants epigenetically suppressed in phenylalanine ammonia lyase expression do not develop systemic acquired resistance in response to infection by tobacco mosaic virus. Plant J. 10:281-293.

Pattery, T., Hernalsteens, J.-P., and De Greve, H. 1999. Identification and molecular characterization of a novel Salmonella enteritidis pathogenicity isolate encoding an ABC transporter. Mol. Microbiol. 33:791-805.

Press, C. M., Loper, J. E., and Kloepper, J. W. 2001. Role of iron in rhizobacteria-mediated induced systemic resistance of cucumber. Phytopathology 91:593-598.

Press, C. M., Wilson, M., Tuzun, S., and Kloepper, J. W. 1997. Salicylic acid produced by Serratia marcescens 90-166 is not the primary determinant of induced systemic resistance in cucumber or tobacco. Mol. Plant-Microbe Interact. 10:761-768

Ras, G. J., Anderson, R., Taylor, G. W., Savage, J. E., Van Niekerk, E., Wilson, R., and Cole, P. J. 1990. Proinflammatory interactions of pyocyanin and 1-hydroxyphenazine with human neutrophils in vitro. J. Infect. Dis. 162:178-185.

Reimmann, C., Serino, L., Beyeler, M., and Haas, D. 1998. Dihydroaeruginoic acid synthetase and pyochelin synthetase, products of the $P c h E F$ genes, are induced by extracellular pyochelin in Pseudomonas aeruginosa. Microbiology 144:3135-3148.

Serino, L., Reimmann, C., Baur, H., Beyeler, M., Visca, P., and Haas, D. 1995. Structural genes for salicylate biosynthesis from chorismate in Pseudomonas aeruginosa. Mol. Gen. Genet. 249:217-228.

-Serino, L., Reimmann, C., Visca, P., Beyeler, M., Della Chiesa, V., and Haas, D. 1997. Biosynthesis of pyochelin and dihydroaeruginoic acid requires the iron-regulated pchDCBA operon in Pseudomonas aeruginosa. J. Bacteriol. 179:248-257.

Simon, R., Preifer, U., and Puhler, A. 1983. A broad host range mobiliza- 
tion system for in vivo genetic engineering: Transposon mutagenesis in gram-negative bacteria. Biotechnology 1:784-791.

Smith-Becker, J., Marios, E., Huguet, E. J., Midland, S. L., Sims, J. J., and Keen, N. T. 1998. Accumulation of salicylic acid and 4-hydroxybenzoic acid in phloem fluids of cucumber during systemic acquired resistance is preceded by a transient increase in phenylalanine ammonia lyase activity in petioles and stems. Plant Physiol. 116:231-238.

-Tambong J. T, and Höfte, M. 2001. Phenazines are involved in biocontrol of Pythium myriotylum on cocoyam by Pseudomonas aeruginosa PNA1. Eur. J. Plant Pathol. 107:511-521.

Turner, J. M., and Messenger, A. J. 1986. Occurrence, biochemistry and physiology of phenazine pigment production. Adv. Microb. Physiol. 27:211-275.

Van Haute, E., Joos, H., Maes, M., Warren, M., and Van Montagu, M. 1983. Intergenic transfer and recombination of restriction fragments cloned in pBR322: A novel strategy for the reversed genetics of the $\mathrm{Ti}$ plasmid of Agrobacterium tumefaciens. EMBO. (Eur. Mol. Biol. Organ.) J. 2:411-417.

van Loon, L. C., Bakker, P. A. H. M., and Pieterse, C. M. J. 1998. Systemic resistance induced by rhizosphere bacteria. Annu. Rev.
Phytopathol. 36:453-483.

Visca, P., Ciervo, A., Sanfilippo, V., and Orsi, N. 1993. Iron-regulated salicylate synthesis by Pseudomonas spp. J. Gen. Microbiol. 139:19952001.

Wilson, K. 1990. Preparation of genomic DNA from bacteria. Pages 2.4.1-2.4.2 in: Current Protocols in Molecular Biology. F. M. Ausubel, R. Brent, R. E. Kingston, D. D. Moore, J. G. Seidman, J. A. Smith, and K. Struhl, eds. J. Wiley and Sons, Boston.

Woodcock, D. M., Crowther, P. J., Doherty, J., Jefferson, S., DeCruz, E., and Noyer-Weidner, M. 1989. Quantitative evaluation of Escherichia coli host strains for tolerance to cytosine methylation in plasmid and phage recombinants. Nucleic Acids Res. 17:3469-3478.

-Yanisch-Perron, C., Vieira, J., and Messing, J. 1985. Improved M13 phage cloning vectors and host strains: Nucleotide sequences of the M13mp18 and pUC19 vectors. Gene 33:103-119.

\section{AUTHOR-RECOMMENDED INTERNET RESOURCE}

The Pseudomonas DNA and protein database: www.pseudomonas.com 